\title{
Estudios preliminares de propagación in vitro de una especie endémica de Chile, Vestia foetida (Solanaceae)
}

\section{Preliminary studies in vitro propagation of an endemic species to Chile, Vestia foetida (Solanaceae)}

\author{
Matilde E. Uribe ${ }^{1,2 \star}$, Catherine Delaveau ${ }^{1}$, Kelly Paredes ${ }^{1}$, Pedro Carrasco ${ }^{1} \&$ Cristian Flores $^{1}$ \\ 1'Universidad de Concepción, Centro Biotecnología-Laboratorio de Cultivo de Tejidos Vegetales, Casilla 160-C, Concepción, \\ Chile. \\ ${ }^{2}$ Departamento de Silvicultura, Facultad de Ciencias Forestales. Victoria 631, Barrio Universitario, Casilla 160-C, Concepción, \\ Chile. \\ *muribe@udec.cl
}

\begin{abstract}
The in vitro germination of seeds of Vestia foetida (Ruiz et Pav.) Hoffmanns. and their multiplication was performed. A $20 \%$ in vitro germination was obtained. The best proliferation medium was MS supplemented with BAP (1.0 mg L-1) plus AIB ( $\left.0.01 \mathrm{mg} \mathrm{L}^{-1}\right)$, with an average of 1.7 new axillary buds per microshoot after two subcultures.
\end{abstract}

La constante búsqueda de nuevas formas y colores ha llevado a la industria de la floricultura a buscar nuevos cultivos y especies (Brickell 2000). Vestia foetida (Ruiz et Pav.) Hoffmanns. conocida vulgarmente como huevil, es una especie endémica, monotípica, perteneciente a la familia Solanaceae que crece en los matorrales húmedos (Hunziker 2001), tanto en la Cordillera de la Costa como en la Precordillera de los Andes, desde la provincia de Valparaíso hasta Chiloé (desde $33^{\circ}$ a $44^{\circ} \mathrm{S}$ ). Es una especie monotípica poco común (Hoffmann 1997). Su fruto es una cápsula de 2 a $3 \mathrm{~cm}$ de longitud, que contiene numerosas semillas (Hoffmann 1997). La planta expele un olor desagradable por la presencia de alcaloides, lo cual la hace una especie interesante como fuente de metabolitos secundarios y puede ser considerada como una planta ornamental por lo llamativo de sus flores (Fig. 1). Además es una planta utilizada en la medicina popular como cura de la disentería y apendicitis (Hoffmann 1997). No existen antecedentes de micropropagación de la especie, sólo existen publicaciones en las que se detalla el envenenamiento de ganado al consumir esta planta (Brevis et al. 2005), sin embargo se reconoce como una especie difícil de propagar a partir de semillas, debido a su lenta germinación. Es por ello que el objetivo del presente trabajo fue introducir y establecer in vitro semillas de Vestia foetida y lograr su multiplicación, con la finalidad de buscar nuevas alternativas de producción de la especie.

Se recolectaron semillas de Vestia foetida de la población ubicada en el sector de Chaimávida, prov. de Concepción (36 $49^{\prime}$ 'S; $\left.72^{\circ} 56^{\prime} \mathrm{W}\right)$. Se utilizaron 39 semillas, las que previo a su introducción in vitro fueron embebidas en agua corriente más ácido giberélico $\left(\mathrm{GA}_{3} 300 \mathrm{ppm}\right)$, durante $24 \mathrm{~h}$. Transcurrido este periodo se realizó una asepsia superficial que consistió en una inmersión en etanol $70 \%(\mathrm{v} / \mathrm{v})$ durante 1 min, 3 enjuagues consecutivos en agua destilada estéril, de 2 min cada uno, hipoclorito de sodio $50 \%$ (v/v; Clorinda ${ }^{\circledR}$, $5 \%$ cloro activo) más dos gotas de surfactante (Quix $\left.{ }^{\circledR}\right)$ por 15 min y finalmente 3 enjuagues consecutivos en agua destilada estéril, de 2 min cada uno. Se extrajeron los embriones y se introdujeron en tubos de ensayo conteniendo $20 \mathrm{ml}$ de medio de cultivo MS (Murashige \& Skoog 1962) con macronutrientes diluidos a un cuarto, $30 \mathrm{~g} \mathrm{l}^{-1}$ de sacarosa, 7 $\mathrm{g} \mathrm{l}^{-1}$ de agar bacteriológico $\left(\right.$ Merck $^{\circledR}$ ). Se ajustó el pH a 5,8 antes de ser autoclavado. Los tubos se incubaron en cámara de crecimiento a $25 \pm 1{ }^{\circ} \mathrm{C}$ en oscuridad por 7 días. Tras este periodo los cultivos fueron trasladados a fotoperiodo de $16 / 8$ h de luz fría y una intensidad luminosa de $40 \mu \mathrm{mol}$ $\mathrm{m}^{-2} \mathrm{~s}^{-1}$, para finalizar su germinación.

Finalizada la germinación se escindieron los ápices caulinares (explantes iniciales) y se aumentó el número de microtallos en medio MS con macronutrientes completos. Para ello se realizó un ensayo de proliferación con los microtallos provenientes del subcultivo $\left(\mathrm{S}_{1}\right)$ con el objetivo de evaluar el efecto de distintas concentraciones de reguladores del crecimiento sobre la capacidad de multiplicación de la especie (Tabla I). Con este fin se utilizó un diseño experimental completamente al azar con el objetivo de determinar diferencias entre ellos mediante análisis de varianza ANDEVA, y se aplicó el test no paramétrico de Kruskal-Wallis, utilizando el paquete estadístico InstDemo. 
Cada tratamiento se repitió 8 veces, considerando como unidad experimental un recipiente con 2 explantes (microtallos) cada uno y 2 subcultivos de 30 días cada uno. Después de dos meses se evaluó ausencia o presencia de raíces espontáneas y número de nuevos brotes.

Después de 30 días se obtuvo un 13\% de germinación, luego de 50 días el porcentaje aumentó gradualmente (Fig. 2). Aun utilizando concentraciones elevadas de $\mathrm{GA}_{3}$, la cantidad de semillas germinadas fue relativamente baja (20\%). Vestia foetida es una especie mucho más difícil de germinar en cultivo in vitro, en comparación a otras especies de la misma familia, como por ejemplo, Solanum lycopersicum L. cuya germinación demora aproximadamente 3 días (Soressi et al. 2009); mientras que semillas de $S$. cajanumensis Kunth, a las que se les aplicó diferentes tratamientos pre-germinativos, tardan entre 5-20 días en germinar, obteniéndose un 92,6\% de germinación (Yaguache 2009) y el tomate de árbol, Cyphomandra betacea (Cav.) Sendtn. demora entre 5-10 días, obteniéndose un alto porcentaje de germinación (98\%) (Contreras \& Almeida 2003).

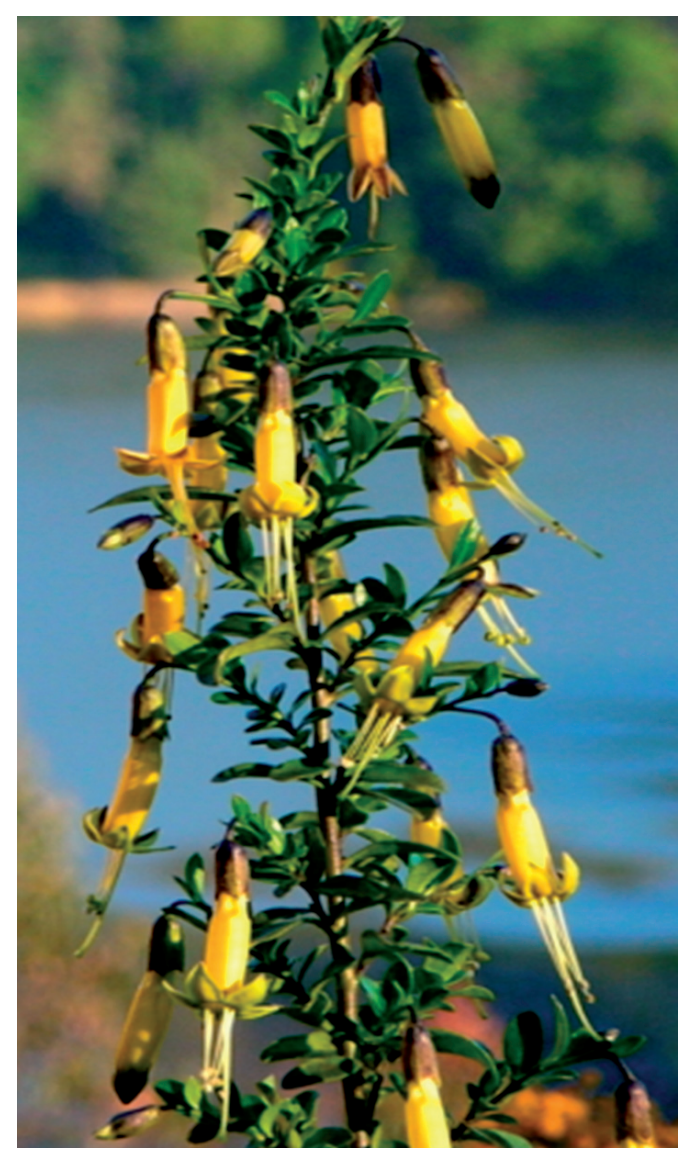

Figura 1. Fotografía de Vestia foetida (Ruiz et Pav.) Hoffmanns.

Figure 1. Photography of Vestia foetida (Ruiz et Pav.) Hoffmanns.
Luego de dos subcultivos no se obtuvo diferencias significativas entre los tratamientos de reguladores del crecimiento aplicados (Tabla II), sin embargo, se observó que el aumento de la concentración de estos reguladores en el medio inhibió el enraizamiento espontáneo, llegando a ser nulo en el segundo subcultivo, en los tratamientos con mayor concentración de reguladores del crecimiento T2 y T3 (78 y 51 microtallos respectivamente). Por otro lado, en ambos subcultivos en medio libre de hormonas, la propagación continuó y las plantas enraizaron espontáneamente (62\%).

El efecto del aumento de la concentración de BAP (bencilaminopurina) redujo la formación de raíces y con esto se estimuló el crecimiento apical, lo que llevó a que se formara una mayor cantidad de brotes por subcultivo (Figs. 3A-E). Resultados similares fueron obtenidos por Matsouka \& Hinata (1979) en Solanum melongena L., quienes reportaron que al añadir BAP al medio se incrementa la formación de vástagos, pero se inhibía la de raíces y la producción de embriones somáticos. Lo mismo ocurre en $S$. cajanumensis, donde la mayor brotación se obtuvo a concentraciones más elevadas de citoquininas que las utilizadas en este estudio, obteniéndose 10,06 brotes por explanto a los 90 días de cultivo (Yaguache 2009).

Al igual que otras solanáceas, $V$. foetida responde relativamente bien al ser cultivada in vitro, en términos de regenerar nuevos brotes de forma directa (1,7 brotes/ explante), lo cual facilita la implementación de cualquier programa dirigido a la propagación clonal masiva así como al mejoramiento genético con fines determinados.

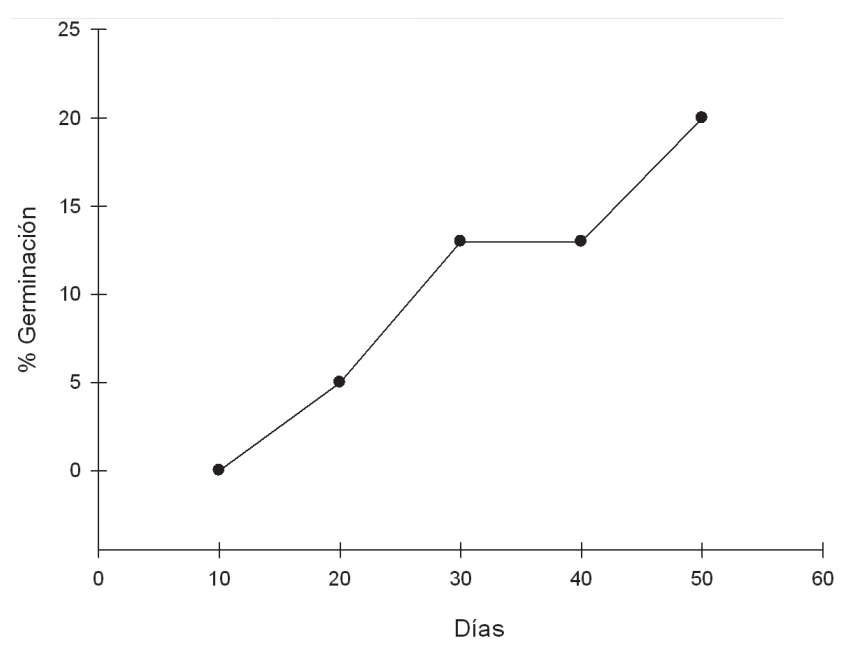

Figura 2. Germinación de semillas de Vestia foetida en medio $\mathrm{MS}^{1} / 4$.

Figure 2. Vestia foetida seed germination on $\mathrm{MS}^{1} 1 / 4$ medium. 
TABLA I. Reguladores del crecimiento para la fase de multiplicación de microtallos de Vestia foetida.

TABLE I. Growth regulators for the multiplication phase of microshoots of Vestia foetida.

\begin{tabular}{ccc}
\hline Tratamiento & BAP $\left(\mathrm{mg} \mathrm{L}^{-1}\right)$ & AIB $\left(\mathrm{mg} \mathrm{L}^{-1}\right)$ \\
\hline T0 & 0 & 0 \\
T1 & 0.1 & 0.01 \\
T2 & 0.5 & 0.01 \\
T3 & 1.0 & 0.01 \\
\hline
\end{tabular}

$\mathrm{AIB}=$ ácido 3-indolbutírico, $\mathrm{BAP}=6$-bencilaminopurina, $\mathrm{T} 0=$ tratamiento control. $/ \mathrm{AIB}=$ indole 3 -butyric acid, $\mathrm{BAP}=$ benzilaminopurine , $\mathrm{T} 0=$ control treatment

TABLA II. Efecto de los reguladores del crecimiento sobre la producción de nuevos brotes axilares en microtallos de Vestia foetida, después de dos subcultivos.

TABLE II. The effect of growth regulators on new axillary buds production of Vestia foetida microshoots after two subcultures.

\begin{tabular}{ccc}
\hline Tratamientos & $\mathrm{N}^{\mathbf{o}}$ EXPlantes & $\mathrm{N}^{\mathbf{o}}$ BROTES \\
\hline T0 & 37 & $1.10 \pm 0.24$ \\
$\mathrm{~T} 1$ & 65 & $1.10 \pm 0.11$ \\
$\mathrm{~T} 2$ & 78 & $1.39 \pm 0.16$ \\
$\mathrm{~T} 3$ & 51 & $1.65 \pm 0.21$ \\
\hline
\end{tabular}

$\mathrm{AIB}=$ ácido 3-indolbutírico, $\mathrm{BAP}=$ Bencilaminopurina, $\mathrm{T} 0=$ tratamiento control, $\mathrm{T} 1=0.1 \mathrm{BAP}+0.01 \mathrm{AIB}, \mathrm{T} 2=0.5 \mathrm{BAP}+0.01 \mathrm{AIB}$, $\mathrm{T} 3=1.0 \mathrm{BAP}+0.01 \mathrm{AIB}, \pm \mathrm{E} . \mathrm{E} . / \mathrm{AIB}=$ indole 3-butyric acid, $\mathrm{BAP}=6$-bencilaminopurina $\mathrm{T} 0=$ control treatment, $\mathrm{T} 1=0.1 \mathrm{BAP}+0.01$ $\mathrm{IBA}, \mathrm{T} 2=0.5 \mathrm{BAP}+0.01 \mathrm{IBA}, \mathrm{T} 3=1.0 \mathrm{BAP}+0.01 \mathrm{IBA}, \mathrm{S} . \mathrm{E}$.

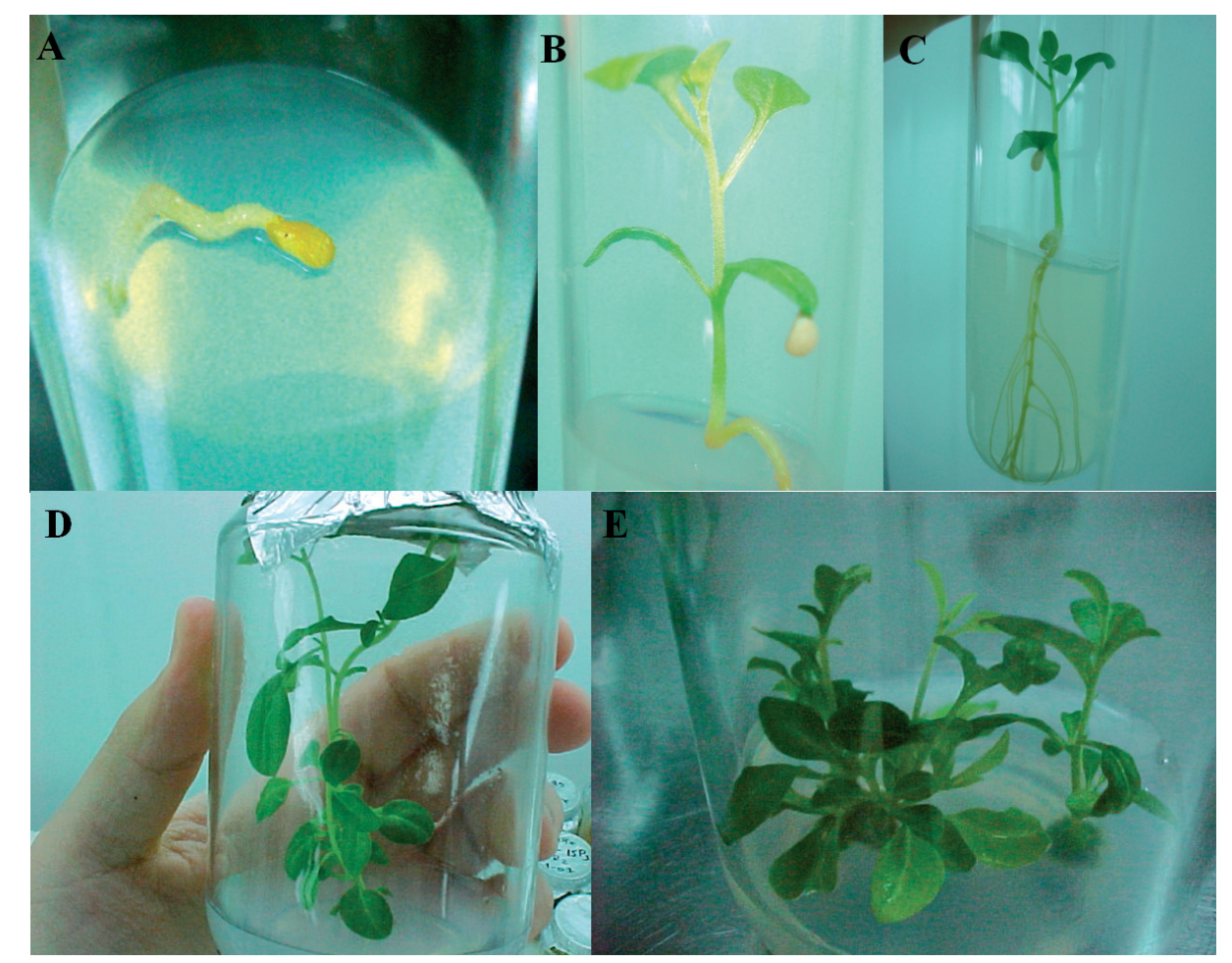

FIgURA 3. Regeneración directa de Vestia foetida a partir de ápices caulinares. A. Semilla germinada in vitro, B y C. Plántula, D. Microplantas después del primer subcultivo, E. Microplantas después del segundo subcultivo con formación de nuevos brotes axilares.

FIgURE 3. Direct regeneration of Vestia foetida from shoot tips. A. In vitro seed germination, B and C. Seedlings, D. Microplants after the first subculture, E. Microplants after the second subculture with formation of new shoot buds. 
Los reguladores del crecimiento vegetal utilizados en esta investigación son buenos inductores de la morfogénesis, lo que indica que esta técnica in vitro puede ser usada para complementar la propagación tradicional. Sin embargo, el utilizar elevadas concentraciones de reguladores del crecimiento conduce a que se produzca una hiperhidricidad de los tejidos por la gran absorción de agua desde el medio, por tanto se debe utilizar bajas concentraciones de reguladores del crecimiento.

\section{AGRADECIMIENTOS}

Los autores agradecen al Dr. Jaime Rodríguez G. por la donación de las semillas, la fotografía de la especie en su hábitat y por incentivar a realizar esta investigación.

\section{BIBLIOGRAFÍA}

Brevis, C., M. Quezada, P. Bustamante, L. Carrasco, A. Ruiz \& S. Donoso. 2005. Huevil (Vestia foetida) poisoning of cattle in Chile. Veterinary Record 156: 452-453.

Brickell, CH. 2000 (ed.). Enciclopedia de plantas y flores (The
Royal Horticultural Society). Grijalbo, Barcelona. 744 pp. Contreras I. \& J. Almeida. 2003. Micropropagación del tomate de árbol (Cyphomandra betacea (Cav.) Sendtn.) Solanaceae silvestre usada en la alimentación humana. Revista Forestal Venezolana 47(2): 9-13.

Hoffmann, A. 1997. Flora Silvestre de Chile, Zona Araucana. Ed. Fundación Claudio Gay. Cuarta edición, 258 pp.

HunziKer, A. T. 2001. Genera Solanacearum. The genera of Solanaceae illustrated, arranged according to a new system. Nicotiana 49-53.

Matsouka, H. \& K. HinatA. 1979. NAA-Induced organogenesis and embryogenesis on hypocotyl callus of Solanum melongena L. Journal Experimental Botany 30: 367-370.

Matthei, O. 1995. Manual de las malezas que crecen en Chile. $1^{\text {er }}$ ed. Santiago, Alfabeta Impresores. Santiago. 545 pp

Murashige, T. \& F. Skoog. 1962. A revised medium for rapid growth and bioassays with tobacco tissue cultures. Physiology Plantarum 15: 473-497.

Soressi, G.P., G. CAMmareri \& M.E. Picarella. 2009. Improvement of in vitro vegetative propagation technique in tomato (Solanum lycopersicum). Acta Horticulturae 812: 283-288.

YAGUACHE, A. 2009. Germinación, brotación y conservación in vitro de Solanum cajanumensis Kunth (tomate de árbol silvestre). Tesis para optar al título de Ingeniero Agropecuario. Universidad Técnica Particular de Loja, Ecuador. 47 pp.

Recibido: 22.07.11

Aceptado: 25.11.11 